\title{
Otimização da resolutividade no cuidado em Medicina de Família e Comunidade por meio do apoio matricial: relato de experiência
}

Optimization to solving the care in family medicine and community through the matrix support: experience report

\section{João Carlos de Souza Côrtes Júnior, Edsneider Rocha Pires de Souza, Maria Cristina Almeida de Souza, Renan Vinícius Santos de Oliveira, Eduardo Herrera Rodrigues de Almeida Júnior.}

\begin{abstract}
Resumo
Apoio matricial é um novo modo de produzir saúde em que duas ou mais equipes, em um processo de construção compartilhada, elaboram um diagnóstico e criam uma proposta de intervenção pedagógico-terapêutica. Configura-se como um suporte técnico especializado que é ofertado a uma equipe interdisciplinar de saúde a fim de ampliar seu campo de atuação, qualificar e otimizar a resolutividade das ações prestadas. Relata-se a experiência da elaboração conjunta de proposta diagnóstica e terapêutica pelo Médico de Família e Comunidade de uma Unidade Estratégia Saúde de Família (ESF) do município de Vassouras/RJ, com o apoio do médico especialista em dermatologia do nível secundário da rede de atenção à saúde (RAS), por meio de apoio matricial. Concluiu-se que o apoio matricial propiciou o compartilhamento de saberes, a construção de novos processos de trabalho que viabilizaram a resolutividade do caso. Palavras-chave: Apoio ao planejamento em saúde. Apoio ao desenvolvimento de recursos humanos. Medicina de Família e Comunidade.
\end{abstract}

Como citar esse artigo. Júnior JCSC, Souza ERP, Souza MCA, Oliveira RVS, Júnior EHRA. Otimização da resolutividade no cuidado em Medicina de Família e Comunidade por meio do apoio matricial: relato de experiência. Revista de Saúde. 2015 Jul./Dez.; 06 (2): 27-29.

\begin{abstract}
Matrix support is a new way to produce health that two or more teams, in a shared building process, develop a diagnosis and create a proposal for a pedagogical and therapeutic intervention. Set up as a specialized technical support that is offered to an interdisciplinary team of health in order to extend their field, qualify and optimize the solving of given actions. It is reported the experience of joint development of diagnostic and therapeutic proposal by Family and Community Medical Unit of Family Health Strategy in the city of Vassouras / RJ, with the support of medical specialist in dermatology at the secondary level of network health care by means of matrix support. It was concluded that the matrix support facilitated knowledge sharing, the construction of new work processes that enabled the solving of the case. Keywords: Support for health planning. Supporting the development of human resources. Family and Community Medicine
\end{abstract}

\section{Introdução}

Recurso de gestão que possibilita a organização das ações de saúde especializadas na atenção básica e amplia o acesso nas equipes de saúde da família, o apoio matricial favorece a construção de novos arranjos organizacionais onde, com uma equipe mais qualificada, é possível pensar cada situação dentro de sua especificidade, sob diferentes olhares. ${ }^{1}$

Conceitua-se apoio matricial como um novo modo de produzir saúde em que duas ou mais equipes, em um processo de construção compartilhada, criam uma proposta de intervenção pedagógico-terapêutica. Configura-se este apoio matricial, também chamado de matriciamento, como um suporte técnico especializado que é ofertado a uma equipe interdisciplinar de saúde a fim de ampliar seu campo de atuação, qualificar e otimizar a resolutividade das ações.
Esta nova proposta integradora visa a transformar a lógica tradicional dos sistemas de saúde representados por encaminhamentos, referências e contrarreferências, protocolos e centros de regulação. Os efeitos burocráticos e pouco dinâmicos dessa lógica tradicional podem vir a ser atenuados por ações horizontais que integrem os componentes e seus saberes nos diferentes níveis assistenciais. Na horizontalização decorrente do processo, o sistema de saúde se reestrutura em dois tipos de equipes denominadas de referência e de apoio matricial. $^{2}$

A equipe de referência, composta por profissionais considerados essenciais para conduzir os problemas de saúde mais comuns da população, está representada pela equipe da Estratégia Saúde da Família, possibilitando um rearranjo organizacional no reforço ao trabalho da equipe multidisciplinar. Já a equipe de apoio matricial é aquela responsável pela 
retaguarda assistencial e o suporte técnico pedagógico de profissionais especialistas às equipes de referência, reforçando a vontade de mudanças nas relações de trabalho.

A proposta de apoio matricial e equipe de referência foi desenhada com o objetivo de superar as limitações impostas pela organização tradicional dos serviços de saúde e ampliar as possibilidades de integração dialógica entre diversas especialidades. ${ }^{3}$

O objetivo deste artigo é relatar a experiência decorrente da elaboração conjunta de proposta diagnóstica e terapêutica, pelo dermatologista do nível secundário da rede de atenção à saúde (RAS) e pelo Médico de Família e Comunidade de uma Unidade Estratégia Saúde de Família (ESF) do município de Vassouras/RJ, por meio de apoio matricial.

\section{Descrição da Experiência}

Usuário do gênero masculino, 38 anos, compareceu à Unidade Estratégia Saúde da Família (ESF) relatando ao Médico de Família e Comunidade que sua queixa principal se devia às lesões na face.

$\mathrm{Na}$ anamnese e na avaliação do genograma, não foi registrada a presença de lesões similares em outros membros da família; registrou-se histórico de crises convulsivas e distúrbio mental no indivíduo. Ao exame físico observou-se a presença de adenomas sebáceos no nariz, queixo e malares.

Em consequência da indefinição diagnóstica de lesão dermatológica de usuário, o Médico de Família e Comunidade de unidade ESF solicitou suporte de especialista, por meio de apoio matricial, a fim de construir conjuntamente um diagnóstico e um plano terapêutico capaz de resolver o caso.

$\mathrm{O}$ atendimento à solicitação se deu em etapas. Primeira: sensibilização do especialista para prestar o apoio matricial. Na segunda etapa, coube ao Médico de Família e Comunidade acompanhar o atendimento prestado pelo especialista ao usuário na unidade ESF. $\mathrm{Na}$ terceira etapa, estruturou-se capacitação para que os MFC de outras unidades ESF e especialistas aprimorassem protocolos, contribuindo para aumento da resolubilidade da atenção.

Baseado nos Critérios de Gomes, no qual algumas características patognomônicas (critérios maiores) por si só, ou associadas a outras menos peculiares (critérios menores), definem quadro clínico, o dermatologista observou os sinais clínicos: placas de Shagreen, fibromas periungueais e gengivais, lesões no esmalte dentário e diagnosticou a alteração como Esclerose tuberosa, uma facomatose, também referida como doença de Pringle, doença de Bourneville, adenoma sebáceo e epilóia, caracteriza-se pelo crescimento anormal de células de origem ectodérmica e mesodérmica, levando ao aparecimento de quadro clínico variável, cujas principais manifestações incluem deficiência mental, epilepsia e tumores, mais comumente na face, cérebro, coração e rim.

Doença rara, de caráter genético, de padrão autossômico dominante, multissistêmica e que resulta no aparecimento de tumorações benignas habitualmente no cérebro, rins, coração, pulmões, olhos e pele. A primeira descrição da doença, caracterizando as lesões cutâneas faciais com sua típica distribuição nasolabial, data ainda do século passado e é de autoria do dermatologista francês Rayer, citado por Morgan e Wolfort ${ }^{4}$ em seu trabalho de revisão.

\section{Discussão}

As experiências com apoio matricial encontradas na literatura são recentes e relatam, via de regra, as dificuldades e potencialidades da inserção de profissionais especialistas na atenção básica. ${ }^{5}$

Há consenso de que o apoio matricial apresenta duas dimensões: uma assistencial, que irá produzir ação direta sobre as necessidades dos usuários, e outra técnico-pedagógica, com responsabilidade de produzir apoio educativo para as equipes da ESF, compartilhando seu conhecimento específico com toda a equipe. ${ }^{2}$

A responsabilidade sobre os casos não deve ser diluída nem transferida por meio de encaminhamentos, mas, ao contrário, também compartilhada, mantendo o vínculo do usuário com a Equipe de Referência, que poderá, assim, ofertar um cuidado longitudinal. ${ }^{5}$

No diálogo com a Equipe de Saúde da Família (ESF), é muito importante que o matriciador não faça julgamentos bruscos, cuidando sempre para reforçar atitudes positivas, especialmente aquelas que denotem autonomia com responsabilidade e clareza técnica.

O processo de trabalho do apoio matricial pode ser organizado em conjunto com a equipe de referência, através de várias ações como consultas conjuntas, trabalhos educativos, projeto de saúde no Território, Projeto Terapêutico Singular, ações junto aos equipamentos públicos como escolas, creches, igrejas, entre outros. Os atendimentos clínicos são predominantes sobre outras ferramentas de matriciamento, como atendimento domiciliar, discussão e elaboração de planos terapêuticos. ${ }^{5}$

É interessante que o profissional matriciador leve em consideração o motivo do apoio matricial; informações sobre a pessoa, família e o ambiente; existência de fator desencadeante da alteração para a qual foi convidado a auxiliar no diagnóstico e plano terapêutico. 


\section{Conclusão}

O apoio matricial assegura retaguarda especializada e suporte técnico para resolução de problemas de saúde dos usuários na atenção básica. Realização de intervenções conjuntas, construção compartilhada de planos terapêuticos, socialização de saber entre especialista e clínico permitiram compartilhamento da responsabilização pelo cuidado ao usuário. Constatou-se também que constitui um recurso facilitador para equipe Estratégia Saúde da Família (ESF) na elaboração do diagnóstico e do plano de cuidados, aumentando resolubilidade da atenção, evitando encaminhamentos desnecessários a outros níveis de complexidade da atenção.

A partir dessa experiência foi possível concluir que o apoio matricial se dará no sentido de encontro e compartilhamento de saberes, de construção de novos olhares, dispositivos e processos de trabalho, para que, a partir daí, seja possível vislumbrar equipes matriciadoras e matriciadas, capazes de refletir, entender e analisar coletivos para qualificar suas intervenções.

\section{Referências}

1 Arona EC. Implantação do Matriciamento nos Serviços de Saúde de Capivari. Saúde e Sociedade. 2009; v.18, supl.1.

2 Brasil. Ministério da Saúde. Guia Prático de Matriciamento em Saúde. 2011. Disponível em: <https://drive.google.com/ file/d/0B HpM8Lq6o5MZWM5NWE1ZDYtOGQwZi00YzBjLT k5Y2ItOTVhMMzljYWU5MjM3/view?pli=1>. Acesso em: 11 de julho de 2015.

3 Cunha GT, Campos GWS. Apoio Matricial e Atenção Primária em Saúde. Saúde Soc., São Paulo. 2011; v. 20, n. 4, p. 961-970.

4 Morgan JE, Wolfort F. The early history of tuberous sclerosis. Arch. Dermatol. 1979; 115:1317.

5 Oliveira IC, Rocha RM, Cutolo LR. Algumas palavras sobre o NASF: Relatando uma experiência acadêmica. Rev. bras. educ. med., Rio de Janeiro, v. 36, n. 4 , p. 574-580, out./dez. 2012. 